\title{
Climate change and the COVID-19 pandemic
}

\author{
El cambio climático y la pandemia de COVID-19
}

\author{
María del Carmen Lacy-Niebla* \\ Instituto Nacional de Cardiología Ignacio Chávez, Mexico City, Mexico
}

Climate change refers to climatic changes that are directly or indirectly attributed to human activity and that alter the composition of the planet's atmosphere, and which add to climate natural variability that occurs over comparable periods of time. Climate change has existed from the beginning of the planet, either suddenly or gradually, and has been derived from various phenomena, such as variations in solar radiation, periods of intense volcanic activity, meteorite impacts, changes in the planet's orbit and others, but the impact of human activity also causes intense climate change by producing emissions from motor vehicles, industrial activity, the deforestation of our forests and jungles, and by the introduction of pollutants into the atmosphere, biosphere and hydrosphere. Climate change is progressing much faster than all the actions we taking to control it and we expose the planet to irreversible damage.

For centuries, humans have enjoyed what nature offers us, and although in general we value the benefits of a healthy environment, there are sectors that fight against measures for the healthy preservation of this environment, and generally involve political and economic interests. There must be a balance that favors a productive and healthy life with shelter, agriculture, food, fun, culture, reproduction, creativity, and adequate control of organic and inorganic waste.

Population and economic growth demand resources and energy that generate global warming and the loss of ecological systems due to their irrational and unrestricted use. Biological and physical means then become limitations for the adequate growth of the population. If allowed, all species tend to grow exponentially, and the limits are given by the resources required for it.

Population growth leads to limiting the habitat of animals, cornering most species, but mainly rodents, which act as reservoirs for major pandemic diseases. Economic development, which dominates human activity, often ignores the laws of nature that are necessary in order for it to be suitable for life, breaks their natural balance and drives us to non-sustainable development.

Climate change seriously damages the health of both human beings and all other animal species that inhabit the planet, and that of plants as well. In recent years, the impact on health has accelerated, with more frequent heat stroke, dehydration, alterations in mental health, neurological, cardiovascular and kidney health, with an increased frequency and severity of respiratory and systemic viral diseases. The biggest threat to health and social and cultural balance is the belief that global warming and climate change are not real. Experts estimate that warming will reach a $1.5^{\circ} \mathrm{C}$ increase between 2030 and 2050 if it continues to increase at current rate. The impact on biodiversity and ecosystems, including the loss of species, will be greater the higher the global temperature that is reached. We are

\section{Correspondence:}

*María del Carmen Lacy-Niebla

E-mail: maricarlacy@yahoo.com license (http://creativecommons.org/licenses/by-nc-nd/4.0/).

Date of reception: 13-04-2021

Date of acceptance: 21-04-2021

DOI: 10.24875/ACME.M21000219
Available online: $20-10-2021$

Arch Cardiol Mex (Eng). 2021;91(3):237-239

www.archivoscardiologia.com 
altering the temperatures of the seas and the acidity levels of the water, which affects thousands of marine species and their survival. Birds have changed their migration processes and land mammals are also threatened. The great fires that have been caused by increased temperature and decreased rainfall are increasingly more difficult to combat and devastate large areas of forests and rain forests that are essential in the strategies not to exceed the $1.5^{\circ} \mathrm{C}$ we fear so much.

The progressive deterioration of ecosystems due to the food and input production model taken from nature gave rise to the pandemic we are suffering, caused by severe acute respiratory syndrome coronavirus 2 (SARS-CoV-2), and also the latest pandemics in the world.

The pandemic has been another of the great moments of self-destruction that have occurred to the human species. The way the virus entered our lives is a dislocation of the environment brought about by our search for an ever elusive development.

The type of development we have decided to adopt has led to seemingly attractive living standards, but not sustainable at all. Lifestyles are focused on material things. We must not continue to deteriorate ecosystems. We have an obligation to preserve planet Earth.

The of contact with nature gave way to the coronavirus disease 2019 (COVID-19) for a way of life that deeply harmed biodiversity and the environment. We are supposed to be intelligent beings, but we have not been doing it well for having lost the relationship the humans had with nature.

The demand for food, energy, modernity, has driven us to destroy the environment.

We have degraded extensive forest and jungle populations to grow food and raise livestock. Everything we consume has an impact on nature. Deforestation, agricultural development and climate change are causing an increase in vector-borne diseases. The COVID-19 pandemic is the result of the disturbance caused by human activity on nature. In a large number of infectious diseases, the pathogen has lived in another species. These species have been an integral part of ecosystems for hundreds of years, but when humans intervene in their transformation by destroying some component, a significant imbalance is generated. Global health organisations have repeatedly urged for the sale of live wild animals to be halted at different food markets around the world. The origin of more than $75 \%$ of emerging infectious diseases in humans are these animals. The research team that recently visited the city and the Hunan Food Market in Wuhan, China, pointed out that SARS-CoV-2 was surely transmitted from bats to humans by another intermediary animal. The chain that exists between caging wild animals in food markets, their subsequent slaughter with the contamination of food sale areas this entails, constitutes a serious risk for the transmission of various pathogenic microorganisms both for buyers and for those who serve in the markets, and hence their rapid spread to the rest of the population.

Another factor is the threat of invasive species to biodiversity, which generates problems of local fauna or flora loss due to the aggressiveness of their exploitation without adequate biological controls.

When ecosystems are invaded without sustainable management of the seas, meadows, forests and jungles, as well as of mangroves, rivers, and lakes, it is then when there are infectious outbreaks, because an imbalance between predators and their preys is generated.

Humans must learn to give true value to forms of sustainable use. It is our obligation to reduce the loss of ecosystems and give natural resources a wise use.

We are facing an unprecedented global emergency. Climate change and the actions that human beings carry out against the balance in nature are a serious threat to the planet, and yet it seems that the COVID-19 pandemic has made us forget the close relationship that exists between both situations. In recent months, we have reacted to the pandemic rather than to this climate emergency, without knowing the close relationship both have. We must not forget one threat to combat the other, they go hand in hand and are intimately connected.

Biodiversity loss acts as a catalyst for the spread of viruses and infectious diseases.

If we reduce this biodiversity and destroy ecosystems, we make it easier for said viruses to pass to humans. We have forgotten that biodiversity acts as a protective shield, since many species act as hosts of viruses and pathogens that maybe today we have not even detected. To prevent new pandemics, we must protect biodiversity and promote sustainable ecosystems. There is no time to lose. This pandemic has taught us that the planet's health is really in our hands. Excessive production and consumption models need to disappear in order to allow a system that ensures a sustainable use of resources for the next generations.

We have an obligation to reduce motor vehicles, industry, and power plants. We must learn not to waste 
food, since, daily, nearly $35 \%$ of it is thrown away as garbage. We must look for a route of sustainable development. If we have learned anything from the current pandemic, it is the need to manage the sustainability of natural resources. For years, we have changed the laws of nature, we have deforested, accelerated migration of populations from the countryside to the big cities, we have polluted seas, skies, and land, and we use non-renewable resources. By consuming wild species, primarily rodents, we have changed host pathogens, and those hosts are often us humans.

That is why we must bet on a sustainable life system, invest in renewable energies, reduce pollution, global warming and climate change.
The education of the new generations is of vital importance. If we do not act immediately, the planet will undergo irreversible changes, humanity will suffer every day more thirst and hunger and emerging diseases that lead to pandemics like the one we are currently experiencing, and consequently, the world will become increasingly violent and anxious, with massive migrations and serious social problems.

The solution lies in the actions humanity takes immediately, without forgetting the power of education for achieving individual change first and then global change. This is a global challenge that requires coordinated action, but each one of us as individuals must responsibly assume our role on planet Earth. 